FREITAS, L.R. et al. Agentes causadores de infecções urinárias em cães em Rio Verde-GO: ocorrência e determinação da sensibilidade a antimicrobianos. PUBVET, Londrina, V. 5, N. 26, Ed. 173, Art. 1166, 2011.

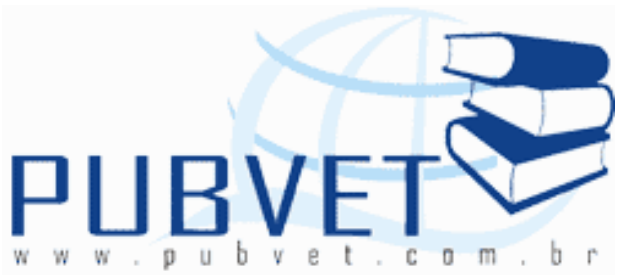

PUBVET, Publicações em Medicina Veterinária e Zootecnia.

\title{
Agentes causadores de infecções urinárias em cães em Rio Verde-GO: ocorrência e determinação da sensibilidade a antimicrobianos
}

\author{
Laressa Rodrigues Freitas ${ }^{1}$, Andréa Cruvinel Rocha Silva ${ }^{2}$, Ariel Eurides \\ Stela ${ }^{3}$, Ednea Freitas Portilho ${ }^{4}$
}

${ }^{\mathbf{1}}$ Acadêmica do Curso de Graduação em Medicina Veterinária - Universidade de Rio Verde (Fesurv). E-mail: laressa_freitas@hotmail.com

${ }^{2}$ Médica Veterinária, Mestranda em Ciência Animal da Universidade Federal de Goiás/ UFG, Professora da disciplina de Prática Hospitalar do curso de Medicina Veterinária/Fesurv - Rio Verde-GO.

${ }^{3}$ Médico Veterinário, Mestre, Doutor, Professor de Microbiologia Veterinária da Universidade Federal de Goiás/UFG- Jataí - GO.

${ }^{4}$ Médica Veterinária, Mestre, Professora das disciplinas: Microbiologia Veterinária e Doenças Infecciosas dos Animais Domésticos I, do curso de Medicina Veterinária/Fesurv - Rio Verde-GO.

\section{Resumo}

As infecções do trato urinário (ITU) usualmente ocorrem quando há uma falha temporária ou permanente nos mecanismos de defesa do hospedeiro e suficiente número principalmente de bactérias que se multiplicam e persistem numa porção do trato urinário. Foram coletadas 26 amostras de urina obtidas por cistocentese em cães com sinais clínicos de ITU, no ano de 2010, no Centro de Controle de Zoonoses e no Hospital Veterinário da Fesurv, situados 
FREITAS, L.R. et al. Agentes causadores de infecções urinárias em cães em Rio Verde-GO: ocorrência e determinação da sensibilidade a antimicrobianos. PUBVET, Londrina, V. 5, N. 26, Ed. 173, Art. 1166, 2011.

no município de Rio Verde-GO, com objetivo de estabelecer o índice de ITU, os agentes etiológicos e o antibiograma. Todas as amostras foram submetidas à urinálise e também à urocultura. Houve bacteriúria em 16 urinálises e apenas quatro amostras com cultura positiva. A identificação das bactérias foi realizada por métodos bioquímicos tradicionais e o antibiograma pelo método de disco-difusão. Houve maior frequência de ITU em fêmeas. As bactérias Gram-negativas isoladas foram Citrobacter sp e Klebsiella sp. E dentre as Gram-positivas, Staphylococcus aureus, S. saprophyticus e S. epidermides foram as mais prevalentes. Os antibióticos nitrofurantoina, tetraciclina, cefalotina, clorafenicol, norfloxacino, eritromicina e enrofloxacino se mostraram eficientes no tratamento das bactérias Gram-positivas e somente cefalotina e enrofloxacino no tratamento das Gram-negativas. Os resultados reforçam a necessidade do conhecimento do perfil de suscetibilidade antimicrobiana das bactérias causadoras de ITU, para evitar o uso incorreto de antibióticos.

Palavras-chave: bactéria, caninos, cistocentese, urina

\title{
Causative agents of urinary infections in dogs in Rio Verde-Go: occurrence and determination of antimicrobial sensitivity
}

\begin{abstract}
The urinary tract infections (UTI) occur usually when there is a temporary or permanent failure in the mechanisms of host defense and sufficient number of mainly bacteria that multiply and persist in a portion of the urinary tract. We collected 26 urine samples obtained by cystocentesis in dogs with clinical signs of UTI, in 2010, the Center for Animal Control and the Veterinary Hospital at Fesurv, located in Rio Verde-GO, with the objective to establish the rate of UTI, the etiologic agents and antibiotic susceptibility. All samples were subjected to urinalysis and urine culture to also. There were bacteriuria in 16 urinalysis and only four samples with positive culture. The identification of the bacteria was performed by traditional biochemical methods and antibiotic susceptibility by
\end{abstract}


FREITAS, L.R. et al. Agentes causadores de infecções urinárias em cães em Rio Verde-GO: ocorrência e determinação da sensibilidade a antimicrobianos. PUBVET, Londrina, V. 5, N. 26, Ed. 173, Art. 1166, 2011.

disk diffusion method. There was a higher incidence of UTI in females. Gramnegative isolates were Citrobacter $s p$ and Klebsiella sp. And among the Grampositive Staphylococcus aureus, S. saprophyticus and S. epidermis were most prevalent. The antibiotic nitrofurantoin, tetracycline, cephalothin, chloramphenicol, norfloxacin, erythromycin and enrofloxacin were effective in the treatment of Gram-positive and only cephalothin and enrofloxacin in the treatment of Gram-negative bacteria. The results reinforce the need for knowledge of antimicrobial susceptibility of bacteria causing UTI, to prevent the misuse of antibiotics.

Keywords: bacteria, canines, cystocentesis, urine

\section{1- INTRODUÇÃO}

As infecções do trato urinário (ITUs) atingem 14\% da população mundial de cães. Podem localizar-se nos rins, bexiga urinária, próstata ou mais de um órgão ao mesmo tempo (BARSANTI e JOHNSON, 1990), sendo as fêmeas e os idosos mais predispostos à infecção (ETÜN et al., 2003).

Há colonização bacteriana somente na porção distal da uretra e genitália externa (vagina ou prepúcio), constituindo-se basicamente de bactérias Grampositivas. Geralmente são bactérias constituintes da microflora intestinal ou porção distal do trato urinário inferior. A contaminação ocorre frequentemente por migração de bactérias pela uretra (via ascendente), mas, pode haver contaminação por via hematógena decorrente de infecções sistêmicas (BARSANTI e JOHNSON, 1990). A infecção ainda pode ser sintomática ou assintomática (BARTGES, 2004).

Os cães apresentam diversos mecanismos de defesa contra ITUs, dentre eles a microflora natural da porção distal da uretra, frequência de micção, anatomia, mucosa vesical, propriedades antimicrobianas da urina e imunidade local e sistêmica (OSBORNE e LEES, 1995).

Quando há falhas em alguns destes mecanismos, aumentam-se as chances de uma infecção. Doenças sistêmicas, como hiperadrenocorticismo e 
FREITAS, L.R. et al. Agentes causadores de infecções urinárias em cães em Rio Verde-GO: ocorrência e determinação da sensibilidade a antimicrobianos. PUBVET, Londrina, V. 5, N. 26, Ed. 173, Art. 1166, 2011.

diabetes mellitus, são predisponentes (MCGUIRE et al., 2002), assim como o uso crônico de glicocorticóides (IHRKE et al., 1985) e o cateterismo vesical, principalmente em fêmeas (LIPPERT et al., 1988).

As ITUs podem ser classificadas como complicadas ou não. No segundo caso, enquadram-se as inferiores bacterianas, nas quais não há falhas nos mecanismos de defesa e respondem bem à antibioticoterapia. Nas complicadas, as falhas são evidentes e, geralmente, urolitíases, neoplasias vesicais, divertículos ou retenção urinária são identificados. Estas falhas devem ser corrigidas para o tratamento ser efetivo (SHAW, 1990).

Na urinálise (EAS) deve-se realizar tanto a análise físico-química, quanto a sedimentoscopia (BASTOS e BICALHO, 2003), pois as fitas reagentes empregadas podem apresentar resultados falsos. Pode haver piúria, hematúria e proteinúria (LEES, 1984; OSBORNE e LEES, 1995). A detecção de bacteriúria pela fita, como nitrito presente, não é confiável em cães, resultando em muitos resultados falso-negativos, pois a excreção de ácido ascórbico na urina inibe a reação química, necessitando da análise do sedimento (VAIL et al., 1986).

Porém bactérias podem não ser visualizadas na sedimentoscopia, não indicando ausência de infecção, sendo necessário urocultura para confirmar (OSBORNE e LEES, 1995). Além disso, casos de ITU oculta (ausência de bactérias e leucócitos no sedimento urinário) podem acontecer em algumas doenças endócrinas (MCGUIRE et al., 2002).

A urocultura é o procedimento mais confiável para o diagnóstico de ITU. Uma cultura bacteriana positiva em amostra de urina coletada por cistocentese antepúbica é confirmatória (COMER e LING, 1981; ALLEN et al., 1987).

São utilizadas alças bacteriológicas calibradas ou pipetas mecânicas na faixa dos microlitros, para semear exatamente 0,01 ou $0,001 \mathrm{~mL}$ de urina em meios próprios para crescimento bacteriano (LULICH et al., 1997). Contagem de organismos inferior a 10.000 bactérias $/ \mathrm{mL}$ sugere contaminação e um número superior a 100.000 indica infecção. Valores entre 10.000 e 100.000 organismos/mL são considerados suspeitos e exige uma nova avaliação (COMER e LING, 1981; ALLEN et al., 1987). 
FREITAS, L.R. et al. Agentes causadores de infecções urinárias em cães em Rio Verde-GO: ocorrência e determinação da sensibilidade a antimicrobianos. PUBVET, Londrina, V. 5, N. 26, Ed. 173, Art. 1166, 2011.

A realização de antibiograma, ou teste de sensibilidade a antimicrobianos, é de extrema importância, devendo ser realizado na sequência da urocultura. A técnica mais empregada é o Kyrbi-Bauer, porém este método tende a subestimar o sucesso do tratamento. Os discos são impregnados com antibióticos em quantidades similares aos níveis plasmáticos alcançados pela droga, mas a concentração urinária de muitas destes é muito superior a esta. Desta forma, algumas bactérias aparentemente resistentes in vitro podem não ser in vivo, devido à maior concentração da medicação na urina (SHAW, 1990).

O tratamento das ITUs varia conforme sua classificação. Nos casos não complicados, a antibioticoterapia resolve o quadro. A escolha do antibiótico deve ser realizada conforme o resultado do teste de sensibilidade do agente (LING, 1984; POLZIN, 1997).

Não existe levantamento brasileiro sobre a prevalência dos agentes envolvidos, nem da sensibilidade destes aos antimicrobianos utilizados rotineiramente na clínica de pequenos animais. Estudos, como este, visam aperfeiçoar o tratamento em casos de ITU inferior em cães e também a orientação dos Médicos Veterinários sobre o uso racional de antimicrobianos, para evitar o surgimento de bactérias super-resistentes.

O objetivo deste trabalho é determinar os agentes causadores de ITU inferior de cães e também estabelecer a sensibilidade dos agentes frente a antimicrobianos usualmente utilizados na rotina clínica veterinária.

\section{2- MATERIAL E MÉTODOS}

Este trabalho foi desenvolvido no Centro de Controle de Zoonozes (CCZ) e no Hospital Veterinário e no Laboratório de Microbiologia da Fesurv Universidade de Rio Verde, em Rio Verde-GO.

Foram coletadas assepticamente 26 amostras de urina, por cistocentese em cães com sinais clínicos de ITU, no ano de 2010. Após colhidas, as amostras eram divididas em dois frascos esterilizados e submetidas à urinálise 
FREITAS, L.R. et al. Agentes causadores de infecções urinárias em cães em Rio Verde-GO: ocorrência e determinação da sensibilidade a antimicrobianos. PUBVET, Londrina, V. 5, N. 26, Ed. 173, Art. 1166, 2011.

e urocultura, em que eram semeadas em Agar nutriente e incubadas a $37^{\circ} \mathrm{C}$ por 24 horas. No EAS verificou-se que em 16 das 26 amostras houve bacteriúria na sedimentoscopia. A identificação das bactérias Gram-negativas foi realizada através de provas bioquímicas tradicionais, como: indol, urease, citrato, VM, VP e a dos cocos Gram-positivos através da prova da catalase, do manitol e da sensibilidade ao disco de novobiocina (OPLUSTIL et al., 2004). Os testes de suscetibilidade aos antimicrobianos foram realizados pelo método descrito pelo NCCLS (2003).

Tanto para as bactérias Gram-negativas quanto para as Gram-positivas, foram testados os antibióticos: ácido nalidíxico, ampicilina, cefalotina, eritromicina, gentamicina, penicilina G, novobiocina, neomicina, tetraciclina, nitrofurantoína, sulfazotrim, cefalexina, enrofloxacino, norfloxacino.

\section{3- RESULTADOS E DISCUSSÃO}

Apesar da bacteriúria em 16 das 26 amostras de urina, somente em quatro houve crescimento bacteriano na urocultura, comprovando assim o que Vail et al. (1986) relataram sobre os resultados falso-positivos no EAS.

Segundo Barsanti e Johnson (1990), há somente colonização bacteriana na porção distal da uretra e genitália externa, constituindo-se basicamente de bactérias Gram-positivas. Detectou-se neste trabalho três isolados Grampositivos e somente dois Gram-negativos.

Para identificação das bactérias Gram-positivas e Gram-negativas foi utilizado o método de coloração de Gram.

Para interpretação de provas bioquímicas e identificação das bactérias Gram-positivas usou-se como base a tabela 1.

$\mathrm{Na}$ amostra oito isolou-se S.aureus, confirmada pelo teste do manitol, na três, S.epidermidis, confirmada pela sensibilidade à novobicina e na 10, S.saprophyticus, confirmada pela resistência à novobiocina (Figura 1). 
FREITAS, L.R. et al. Agentes causadores de infecções urinárias em cães em Rio Verde-GO: ocorrência e determinação da sensibilidade a antimicrobianos. PUBVET, Londrina, V. 5, N. 26, Ed. 173, Art. 1166, 2011.

Tabela 1 - Provas bioquímicas e identificação de bactérias Gram-positivas

\begin{tabular}{cccc}
\hline Provas bioquímicas & S. aureus & S. epidermidis & S. saprophyticus \\
\hline $\begin{array}{c}\text { Catalase } \\
\begin{array}{c}\text { Fermentação do } \\
\text { manitol }\end{array}\end{array}$ Sensibilidade a $_{\begin{array}{c}\text { novobiocina } \\
\text { novion }\end{array}}$ & $\mathrm{R}$ & - & - \\
\hline
\end{tabular}

Fonte: Koneman et al., 2001.

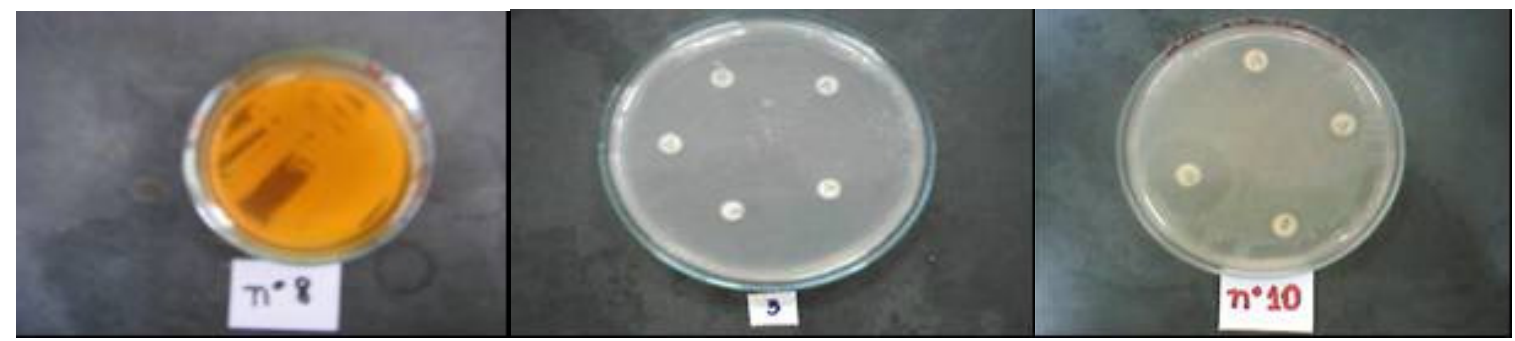

Figura 1 - Identificação das bactérias mostrando a mudança de cor do manitol, a sensibilidade e resistência pelo halo de inibição da novobiocina.

Fonte: Arquivo pessoal

E para interpretação de provas bioquímicas e identificação das bactérias Gram-negativas usou-se como base a tabela 2.

Tabela 2 - Provas bioquímicas e identificação de bactérias Gram-negativas

\begin{tabular}{ccc}
\hline Provas bioquímicas & Citrobacter sp. & Klebsiella sp. \\
\hline Indol & + & - \\
VM & + & - \\
VP & - & + \\
Urease & - & + \\
Citrato & + & + \\
\hline
\end{tabular}

Fonte: Koneman et al., 2001.

Pelas provas bioquímicas foi identificada na amostra seis a bactéria Citrobacter sp. e na amostra oito a bactéria Klebsiella sp. (Figura 2). 
FREITAS, L.R. et al. Agentes causadores de infecções urinárias em cães em Rio Verde-GO: ocorrência e determinação da sensibilidade a antimicrobianos. PUBVET, Londrina, V. 5, N. 26, Ed. 173, Art. 1166, 2011.

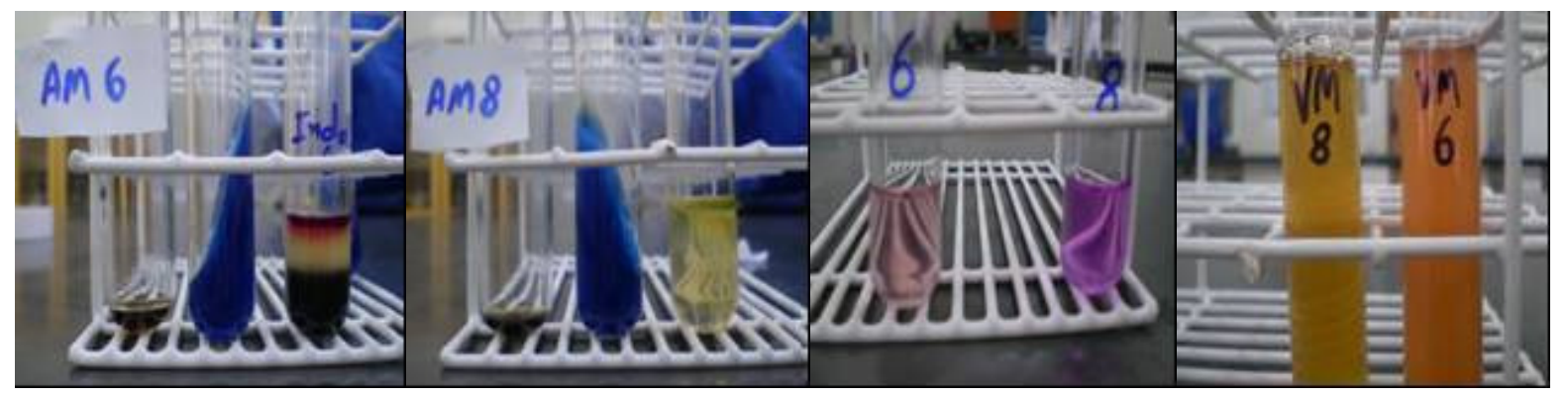

Figura 2 - Diferentes resultados bioquímicos - amostras seis e oito Fonte: Arquivo pessoal

No antibiograma a bactéria que mais teve sensibilidade aos antibióticos foi a S. epidermides, da amostra três, possibilitando o uso de dose comum dos antibióticos nitrofurantoína, tetraciclina e cefalotina, e dosagem máxima de clorafenicol, norfloxacino e eritromicina. Para a Citrobacter sp., da amostra seis, pode-se fazer o uso de norfloxacino, em dosagens altas, devido à sensibilidade intermediária ao antibiótico. Na S. saprohyticus, da amostra 10, pode-se usar o enrofloxacino e o norfloxacino, também em dosagem alta. $\mathrm{Na}$ amostra oito, como houve o crescimento de duas bactérias distintas a S.aureus e a klebsiella sp., o único antibiótico eficaz foi a cefalotina, usado em dosagens altas.

Constatou-se com o presente trabalho a importância dos exames complementares tanto para o diagnóstico da doença quanto para o tratamento com antibiótico específico.

\section{REFERÊNCIAS}

ALLEN, T.A.; JONES, R.L.; PURVANCE J. Microbiologic evaluation of canine urine: Direct microscopic examination and preservation of specimen quality of urine for culture, Journal of the American Veterinary Medical Association, v.190, n.10, p.1289-1291, 1987.

BARSANTI, J.A.; JOHNSON, C.A. Genitourinary Infections. In: GREENE, CE. Infectious Diseases of the Dog and Cat. W.B. Saunders, Philadelphia, EUA, p.157-183, 1990.

BARTGES, J.W. Diagnosis of urinary tract infections. Veterinary Clinical Small Animal, v.34, p.923-933, 2004.

BASTOS, C.V.; BICALHO A.P. Sedimentoscopia em urinas caninas com características físicoquímicas normais: qual seu valor? - Revista Clínica Veterinária. Editora Guará, n.45, 2003. 
COMER, K.M.; LING, G.V. Results of urinalusis and bacterial culture of canine urine obtained by antepubic cystocentesis, catheterization and midstream voided methods. Journal of the American Veterinary Medical Association, p.179-891, 1981.

ETÜN, C.; SENTÜRK, S.; KOCABIYIK, A.L.; TEMÜZEL, M.; ZEL, E. Bacteriological Examination of Urine Samples from Dogs with Symptoms of Urinary Tract Infection. Turkey Journal Veterinary Animal Science, v.27, p.1225-1229, 2003.

IHRKE, P.J.; NORTON, A.L.; LING, G.V.; STANNARD, A.A. Urinary tract infection associated with long-term corticosteroid administration in dog with chronic skin disease. Journal of the American Veterinary Medical Association, v.186, n.1, p.43-46, 1985.

KONEMAN, E.W.; ALLENS, S.D.; JANDA, W.M.; SCHRECKENBERGER, P.C.; WINN JR, W.C. Diagnóstico Microbiológico. 5 ed. Rio de Janeiro: Medsi, p.177-261, 2001.

LEES, G.E. Epidemiology of Naturally Occurring Feline Bacterial Urinary Tract Infections. Veterinary Clinics of North America, v.14, n.3, p.471-479, 1984.

LING, G.V. Therapeutic strategies involving antimicrobial treatment of canine urinary. Journal of the American Veterinary Medical Association, v.185, n.10, p.1162-1164, 1984.

LIPPERT, A.C.; FULTON, R.B.; PARR, A.M. Nosocomial Infection Surveillance in a Small Animal Intensive Care Unit. Journal of the American Animal Hospital Association, v.24, p.627-636, 1988.

LULICH, J.P.; OSBORNE, C.A; BARTGES, J.W.; POLZIN, D.J. Afecções do trato urinário inferior dos caninos. In: ETTINGER S. J.; FELDMAN, E.C. tratado de Medicina Veterinária Moléstias do cão e do gato. São Paulo: Roca, 4 Ed, v.2, p.2496-2533, 1997.

MCGUIRE, N.C.; SCHULMAN, R.; RIDGWAY, M.D.; BOLLERO, G. Detection of Occult Urinary Tract Infections in Dogs with Diabetes Mellitus. Journal of the American Animal Hospital Association, v.38, p.541-544, 2002.

NATIONAL COMMITTEE FOR CLINICAL LABORATORY STANDARDS. Performance standards for antimicrobial disk susceptibility tests. Approved standards. Document M2-A8. Wayne: NCCLS, 58 p. 2003.

OPLUSTIL, C.P.; ZOCCOLI, C.M.; TOBOUTI, N.R.; SINTO, S.I. Microbiologia Clínica, São Paulo, Sarvier, 2 ed, 2004.

OSBORNE, C.A.; LEES, G.E. Bacterial Infections of the Canine and Feline Urinary Tract. In: FINCO, D. R. Canine and Feline Nephrology and Urology. Williams \& Wilkins, Baltimore, EUA, p.759-797, 1995.

POLZIN, D.J. Tratamiento de lãs infecciones bacterianas difíciles dei tracto urinário. Waltham Focus, v.7, n.1, p.13-19, 1997.

SHAW, D.H. A systemic approach to managing lower urinary tract infections. Journal of the American Veterinary Medical Association, v.85, n.4, p.379-386, 1990.

SILVA, V.G. Coloração De Gram. Disponível em: <http://www.fag.edu.br/professores/vgsilva/Microbiologia/Pr\%e1tica\%20\%20Colora\%e7\%e30 \%20de\%20Gram.pdf>. Acesso em: 10 dez/2010.

VAIL, D.M.; ALLEN, T.A.; WEISER, G. Applicability of leukocyte esterase test strip in detection of canine pyuria. Journal of the American Veterinary Medical Association, v.189, n.11, p.1451-1453, 1986. 